\title{
USING A SOIL CHRONOSEQUENCE TO IDENTIFY SOIL FRACTIONS FOR UNDERSTANDING AND MODELING SOIL CARBON DYNAMICS IN NEW ZEALAND
}

\author{
Christine A Prior ${ }^{1} \bullet \mathrm{W}$ Troy Baisden ${ }^{2} \bullet$ Frank Bruhn $^{2} \bullet \mathrm{Jason}^{\mathrm{C}} \mathrm{Neff}^{3}$
}

\begin{abstract}
We are developing practical methodologies to characterize pool sizes and residence times for fractions of soil organic matter (SOM) using radiocarbon, with a particular focus on SOM in New Zealand pasture soils that responds to global change on decadal timescales. As single mean residence times for the entire SOM pool can be misleading or uninterpretable, we focus on the use of samples collected about 7 and $40 \mathrm{yr}$ after the bomb- ${ }^{14} \mathrm{C}$ spike to separate SOM into at least 2 pools. These results from a box model methodology yield sensible estimates of the proportion of "passive" SOM, and the residence time of the dominant pool with approximately decadal residence times. These results are supported by chemical analysis. Approximately 45-yr residence times of light-fraction SOM in a relatively infertile soil contrast with $\sim 16-y r$ residence times in a more fertile soil, and correspond to large differences in the proportion of lignin- and polysaccharide-derived SOM in these soils measured using pyrolysis-GC/MS. To achieve greater detail and assess the degree to which "active" SOM with annual turnover rates may bias results from the simple model, we use density as a means of isolating SOM with different degrees of mineral association. Initial results from grazed pasture soils sampled in 2003-4 emphasize that isolating non-mineralassociated light fractions can improve understanding, but may be less important than identifying fractions associated with unique mineralogy. In this soil, a fraction with density $\geq 2.55 \mathrm{~g} / \mathrm{mL}$ shows much larger proportions of passive SOM than other fractions.
\end{abstract}

\section{INTRODUCTION}

Soil organic matter (SOM) plays an important role in the global carbon cycle, storing more carbon than the biosphere and atmosphere combined, and may release considerable carbon as $\mathrm{CO}_{2}$ in response to climate change, land-use change and management (Amundson 2001). Even with decades of research, fundamental questions remain concerning the exact physical and chemical mechanisms for carbon storage. Recently, the National Isotope Centre at GNS Science in collaboration with Landcare Research began a 5-yr research program to use radiocarbon as a tracer to assess the turnover and storage of carbon in New Zealand soils. The research program will focus on the use of meaningful fractionation methods, and soil respiration, to understand the distribution of residence times found in the New Zealand SOM. Our program also emphasizes the value of archived samples and previous New Zealand soil ${ }^{14} \mathrm{C}$ data (Goh et al. 1976; O'Brien and Stout 1978; Lassey et al. 1996) in augmenting fractionation procedures to provide meaningful characterization of SOM turnover.

Overall, New Zealand presents an exceptional opportunity for the study of soil carbon dynamics. Within its small size, New Zealand has great diversity in the factors that determine soil properties, including climate, vegetation, geology, and topography. While the resulting variation in soil properties can be complex, it is possible to isolate variation in one factor while holding others constant (Jenny 1941). This includes the capability to emphasize variation along a soil age gradient that determines the accumulation of SOM under natural conditions (Syers et al. 1970; Schlesinger 1990). New Zealand's isolation from other land masses has protected it from industrial pollution, including nitrogen deposition and black carbon. Land use has also favored stable pastoral management or forestry, suggesting stable processes controlling SOM levels (Tate et al. 1997). Combined with a complete soil survey archive of soils spanning the bomb- ${ }^{14} \mathrm{C}$ period, these changing land-use patterns present a unique opportunity to study the carbon inventory implications of land-use changes.

\footnotetext{
${ }^{1}$ Rafter Radiocarbon Laboratory, National Isotope Centre, GNS Science, PO Box 31-312, Lower Hutt, New Zealand. Corresponding author. Email: c.prior@gns.cri.nz.

${ }^{2}$ National Isotope Centre, GNS Science, PO Box 31-312, Lower Hutt, New Zealand.

${ }^{3}$ Department of Geological Sciences, University of Colorado, Campus Box 399, Boulder, Colorado 80309, USA.
} 
In this paper, we present preliminary research on the use of density fractionation schemes to isolate soil organic matter (SOM) and assist in determining residence times. We recognize that density fractionation does not directly identify SOM with residence times of several years or less ("active"), decades ("stabilized"), and millennia ("passive"). Instead, we recognize that light fractions $(<1.7 \mathrm{~g}$ / $\mathrm{mL}$ ) are mainly a mixture of "active" and decadal pools (in the absence of significant coarse charcoal that may be passive) and that mineral-associated or dense fractions $(>1.7 \mathrm{~g} / \mathrm{mL})$ are dominated by decadal and millennial SOM (Baisden et al. 2002). We therefore have based our methods on density as a means of isolating SOM with different degrees of mineral association, and expanded the range of fractions considered based on the approach of Sollins et al. (2006).

Sites were chosen where rates of bomb- ${ }^{14} \mathrm{C}$ incorporation can be inferred through published $\Delta{ }^{14} \mathrm{C}$ data in combination with accelerator mass spectrometry (AMS) analysis of archived soils. We have selected relatively young $(\sim 1000 \mathrm{yr})$ and old $(\sim 10,000 \mathrm{yr})$ sites from the well-studied Manawatu sand dune chronosequence in order to understand sites with low and high levels of nutrient and SOM accumulation (Syers et al. 1970). This chronosequence and similar chronosequences have been used to understand the potential soil carbon response to global change (Schlesinger 1990) and the rate of terrestrial carbon accumulation following the retreat of continental ice sheets (Harden et al. 1992). We examined soils under longer-term pasture because grazing is a dominant land use in New Zealand and across the chronosequence, and most New Zealand land-use changes are in or out of pasture. We used recently sampled soils from the chronosequence in tandem with published $\Delta^{14} \mathrm{C}$ data to examine practical methods for characterizing SOM residence times and verifying that the derived residence times can be linked to known differences in soil chemistry and mineralogy.

\section{METHODS}

The sites are a "soil chronosequence" (Jenny 1941) formed on wind-blown sands on the western coast of New Zealand's North Island at $40.5^{\circ} \mathrm{S}$ latitude, with mean annual rainfall of $850 \mathrm{~mm}$ and mean annual temperature of $12{ }^{\circ} \mathrm{C}$ (Syers and Walker 1969). The coast in this region has been aggrading at a rate of $\sim 1 \mathrm{~m} / \mathrm{yr}$, allowing distance to the coast to be used as an approximate surrogate for time. The dune phases and their associated soils are Waitarere ( $50 \mathrm{yr})$, Motuiti $(500-1000 \mathrm{yr})$, Foxton (3000-5000 yr), and Koputaroa ( 10,000 yr). Vegetation succession occurs in concert with soil development: succession proceeds from dune-stabilizing grasses and shrubs (Waitarere) toward temperate evergreen forest under undisturbed conditions on the older soils (Syers et al. 1970). Superimposed on the chronosequence has been the introduction of fire by Polynesian settlement of New Zealand, and the introduction of pastures. The pasture at most sites is believed to have undergone improvement and intensification between the 1970 sampling and 2002-3.

The $1970{ }^{14} \mathrm{C}$ studies on the chronosequence published by Goh et al. (1976) measured the ${ }^{14} \mathrm{C}$ activity of bulk $<2-\mathrm{mm}$ soil, ground to pass a $150-\mu \mathrm{m}$ sieve. Soils from the same sites were resampled in 2002 (Waitarere, Motuiti, Foxton) and 2003 (Koputaroa), and sieved to remove >2-mm material. The dried bulk samples were homogenized by grinding to pass a $180-\mu \mathrm{m}$ sieve and then combusted in evacuated quartz tubes with $\mathrm{CuO}$ and $\mathrm{Ag}$, without pretreatment. Resulting $\mathrm{CO}_{2}$ was reduced to graphite over an iron catalyst and measured at the NIC accelerator facility. The humic extractions performed by Goh et al. (1976) were not repeated.

In addition to $\Delta^{14} \mathrm{C}$ measurements on bulk soil carbon, we attempted to consider more quantitative and detailed methods of examining carbon storage and turnover in soil fractions with different residence times. Initially, following a simplification of the procedure described in Baisden et al. (2002), we separated the soil samples into a "light density fraction" and "dense fraction." In this procedure, the fractions were separated by centrifuging in a solution of sodium polytungstate (SPT). The "light" 
fraction represented floating material $<1.60 \mathrm{~g} / \mathrm{mL}$ and the "dense" fraction was soil material with a density $\geq 1.70 \mathrm{~g} / \mathrm{mL}$. The expectation was that the light density fraction would represent carbon that turns over very quickly and the dense fraction would yield older mineral-associated SOM, but the binary separation of light and dense fractions did not provide sufficient information.

Following the approach of Sollins et al. (2006), we applied a sequential density separation procedure. Samples of the Motuiti and Koputaroa soils were mixed in a SPT solution with density $1.7 \mathrm{~g} /$ $\mathrm{mL}$ and then centrifuged at $3000 \mathrm{rpm}$ for $4 \mathrm{~min}$. Material floating was decanted off into a glass filter funnel containing a 6- $\mu$ m nylon filter. After rinsing several times with $\mathrm{dH}_{2} \mathrm{O}$, this material was collected and labeled the " $<1.70$ " fraction. The soil material that precipitated at $1.7 \mathrm{~g} / \mathrm{mL}$ in the centrifuge tube was then mixed with a SPT solution of $2.3 \mathrm{~g} / \mathrm{mL}$ and centrifuged at $3000 \mathrm{rpm}$ for $4 \mathrm{~min}$. Floating material was collected as before and labeled "1.7-2.3." This procedure was repeated again with SPT of specific gravity (sp.gr.) 2.55 and the resultant 2 fractions were labeled " $2.3-2.55$ " and " $\geq 2.55$." All 4 fractions were rinsed thoroughly with $\mathrm{dH}_{2} \mathrm{O}$ to remove any remaining SPT, then vacuum-dried. Each of the 4 fractions was combusted and converted to graphite for AMS ${ }^{14} \mathrm{C}$ dating. Although this procedure avoided the need to combust quartz fiber filters as described in Baisden et al. (2002), the collection of material on nylon filters resulted in soil recoveries of $96 \%$ and $92 \%$ and carbon recoveries of $78 \%$ and $99 \%$ in the Motuiti and Koputaroa soils, respectively. We accepted these recoveries, noting that some $\mathrm{C}$ is frequently lost to dissolution during fractionation with SPT (Baisden et al. 2002). Ideally, losses should be better quantified or further limited in future studies.

Pyrolysis-gas chromatography/mass spectroscopy (py-GC/MS) analyses on the 0- to 8-cm levels of Motuiti and Koputaroa soils were carried out at the University of Colorado. Soil samples were pyrolyzed (10 s) in a GSG Analytical Pyromat Curie-point pyrolyzer using a ferromagnetic tube with a Curie-point of $590^{\circ} \mathrm{C}$. The pyrolysis products were transferred online to a Trace GC gas chromatograph. The interface temperature was set to $250{ }^{\circ} \mathrm{C}$, following split injection (split ratio $50: 1, \mathrm{He}$ flow rate $1.0 \mathrm{~mL} / \mathrm{min})$. The pyrolysis products were separated on a BPX 5 column $(60 \mathrm{~m} \times 0.25 \mathrm{~mm}$, film thickness $0.25 \mu \mathrm{m}$ ) using a temperature program of $40^{\circ} \mathrm{C}$ for $5 \mathrm{~min}, 5^{\circ} \mathrm{C} / \mathrm{min}$ to $270{ }^{\circ} \mathrm{C}$, followed by a jump $\left(30^{\circ} \mathrm{C} / \mathrm{min}\right)$ to a final temperature of $300^{\circ} \mathrm{C}$. The injector temperature was set to $250{ }^{\circ} \mathrm{C}$. The column outlet was coupled to a Thermo Polaris- $\mathrm{Q}$ ion-trap mass spectrometer operated at $70 \mathrm{eV}$. The transfer line was heated to $270{ }^{\circ} \mathrm{C}$ and source temperature was held at $200{ }^{\circ} \mathrm{C}$. Pyrolysis products were identified by comparison with reference spectra after deconvolution and extraction using AMDIS v 2.64 and National Institute of Standards and Technology (NIST) mass spectral libraries and published literature (Pouwels et al. 1989; Schulten and Schnitzer 1997). Figure 4 was generated by measuring the relative proportion of compounds in each broad compound class.

We estimated the turnover rate of SOM based on measured $\Delta^{14} \mathrm{C}$ values using an approach similar to the box model presented in Trumbore (1993) and identical to Baisden et al. (2002). The approach recognizes that 2 "pools" of SOM with different residence times can exist within the same soil or soil fraction. We assume 1 pool $\left(C_{p o o l}\right)$ has annual to decadal residence times, while the other pool $\left(C_{\text {passive }}\right)$ is passive (millennial turnover times). The model assumes that both pools have reached an approximate steady state, meaning that the inputs, $I$, are assumed equal to the outputs, defined as the residence time, $k$, multiplied by $C_{\text {pool }}$. Starting in 1909 , the model numerically incorporates $\mathrm{C}$ with ${ }^{a}{ }^{14} \mathrm{C} /{ }^{12} \mathrm{C}$ ratio representing atmospheric $\mathrm{CO}_{2}$ incorporated in plant biomass, taken from Southern Hemisphere atmospheric data (Manning et al. 1994).

$$
\frac{\Delta C_{\text {pool }}}{\Delta t}=\left(I-k C_{\text {pool }}\right) \Delta t
$$




$$
\frac{\Delta\left({ }^{14} C_{\text {pool }}\right)}{\Delta t}=\left(A_{\text {year-lag }} I-(k+\lambda){ }^{14} C_{\text {pool }}\right) \Delta t
$$

In these difference equations, $C_{\text {pool }}$ and ${ }^{14} C_{\text {pool }}$ represent $\mathrm{SOC}$ mass and ${ }^{14} \mathrm{C}$ mass in a portion of the soil fraction, while $\Delta t$ represents a time step and is generally $1 \mathrm{yr}$. Note that $\Delta$ in these equations applies the difference operator and not isotope notation. The ${ }^{14} \mathrm{C} /{ }^{12} \mathrm{C}$ ratio of the atmosphere, $\mathrm{A}_{\text {year }}$ lag, is lagged behind the atmospheric data by $1 \mathrm{yr}$ to represent the approximate residence time of $\mathrm{C}$ in plant biomass. The decay constant for ${ }^{14} \mathrm{C}(\lambda)$ is set to $1.21 \times 10^{-4} \mathrm{yr}^{-1}$. The $\Delta^{14} \mathrm{C}$ of the passive pool was calculated based solely on radioactive decay $(\lambda)$ and assumed residence time, and the $\Delta^{14} \mathrm{C}$ of the modeled fraction is calculated as the mixture of the passive pool $\left(C_{\text {passive }}\right)$ and $C_{\text {pool }}$ in Equations $1 \mathrm{a}$ and $1 \mathrm{~b}$ according to the following equation:

$$
\Delta^{14} C_{\text {fraction }}=\left(1-P_{\text {passive }}\right) \Delta^{14} C_{\text {pool }}+P_{\text {passive }} \Delta^{14} C_{\text {passive }}
$$

$P_{\text {passive }}$ is the proportion $\left[C_{\text {passive }} /\left(C_{\text {passive }}+C_{\text {pool }}\right)\right]$ of the SOC in the sample that is passive C. This value, $P_{\text {passive }}$, is henceforth referred to as fraction passive. The $\Delta^{14} \mathrm{C}$ value of the passive fraction was set for each soil using an approximate value of $-300 \%$ (residence time $3000 \mathrm{yr}$ ) based on Baisden et al. (2002) for all soils except Motuiti. At Motuiti, the $\Delta^{14} \mathrm{C}$ value was set to allow for a residence time of $500 \mathrm{yr}$ due to the younger age of the soil. This $3000-\mathrm{yr}$ residence time was used for the $<100-y r$ Waitarere soil to test for old inherited $\mathrm{C}$ in the wind-blown sand from which the soil formed.

The model was implemented in Microsoft ${ }^{\circledR}$ Excel $^{\circledR}$ with an annual time step. The values of $k$ and $P_{\text {passive }}$ were fitted to the 1970 and 2003-4 data using Microsoft Excel's "solver." The optimized fit minimizes the sum of squared errors between the modeled and measured fraction $\Delta^{14} \mathrm{C}$ obtained for each year a sample was available. The fitting process therefore is using 2 pieces of data to solve for 2 unknowns. Figure 1 presents an example of a box model fit for the Koputaroa soil.

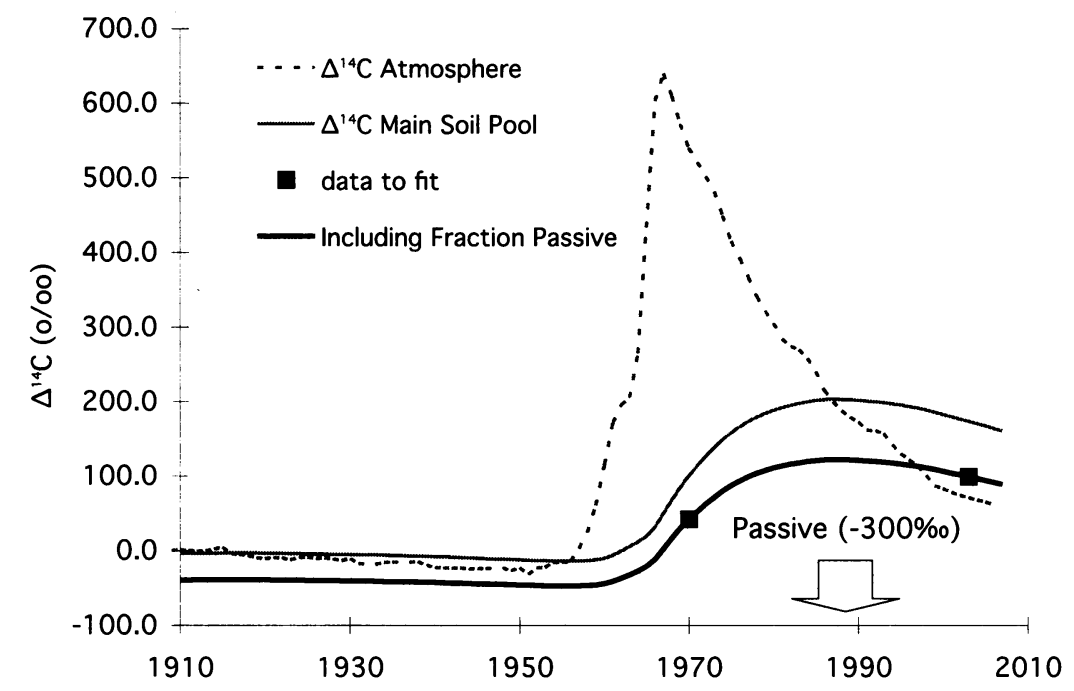

Figure 1 Example of a box model fit for the Koputaroa soil 


\section{RESULTS AND DISCUSSION}

A comparison of the results of our $\Delta^{14} \mathrm{C}$ measurements of whole surface soil samples from the different phases in the Manawatu chronosequence with the measurements published by Goh et al. (1976) is shown in Table 1 and illustrated in association with the Southern Hemisphere atmospheric $\Delta^{14} \mathrm{C}$ curve in Figure 2.

Table 1 Comparison in whole soil samples between measurements made in 1970 (Goh et al. 1970) and 2002-3 (this study). Samples representing shallow depth increments were selected from Goh et al. (1976), regardless of grazing status.

\begin{tabular}{llcl}
\hline Soil age and depth & Year sampled & $\Delta^{14} \mathrm{C}(\%)$ & $\delta^{13} \mathrm{C}(\%)$ \\
\hline Waitarere 0-3 cm & 1970 & $390 \pm 9$ & -26.8 \\
Waitarere A 0-5.5 cm & 2003 & $143.5 \pm 5.2$ & -26.4 \\
& & & \\
Motuiti 0-9 cm & 1970 & $67 \pm 5$ & -27.4 \\
Motuiti 0-8 cm & 2003 & $155.5 \pm 5.1$ & -26.5 \\
Foxton brown 0-10 cm & 1970 & $42 \pm 4$ & -27.5 \\
Foxton 0-7.5 cm & 2003 & $99 \pm 5.5$ & -27.0 \\
Koputaroa 0-11 cm & 1970 & $60 \pm 5$ & -26.2 \\
Koputaroa 0-8 cm & 2004 & $70.7 \pm 5.8$ & -28.2 \\
\hline
\end{tabular}

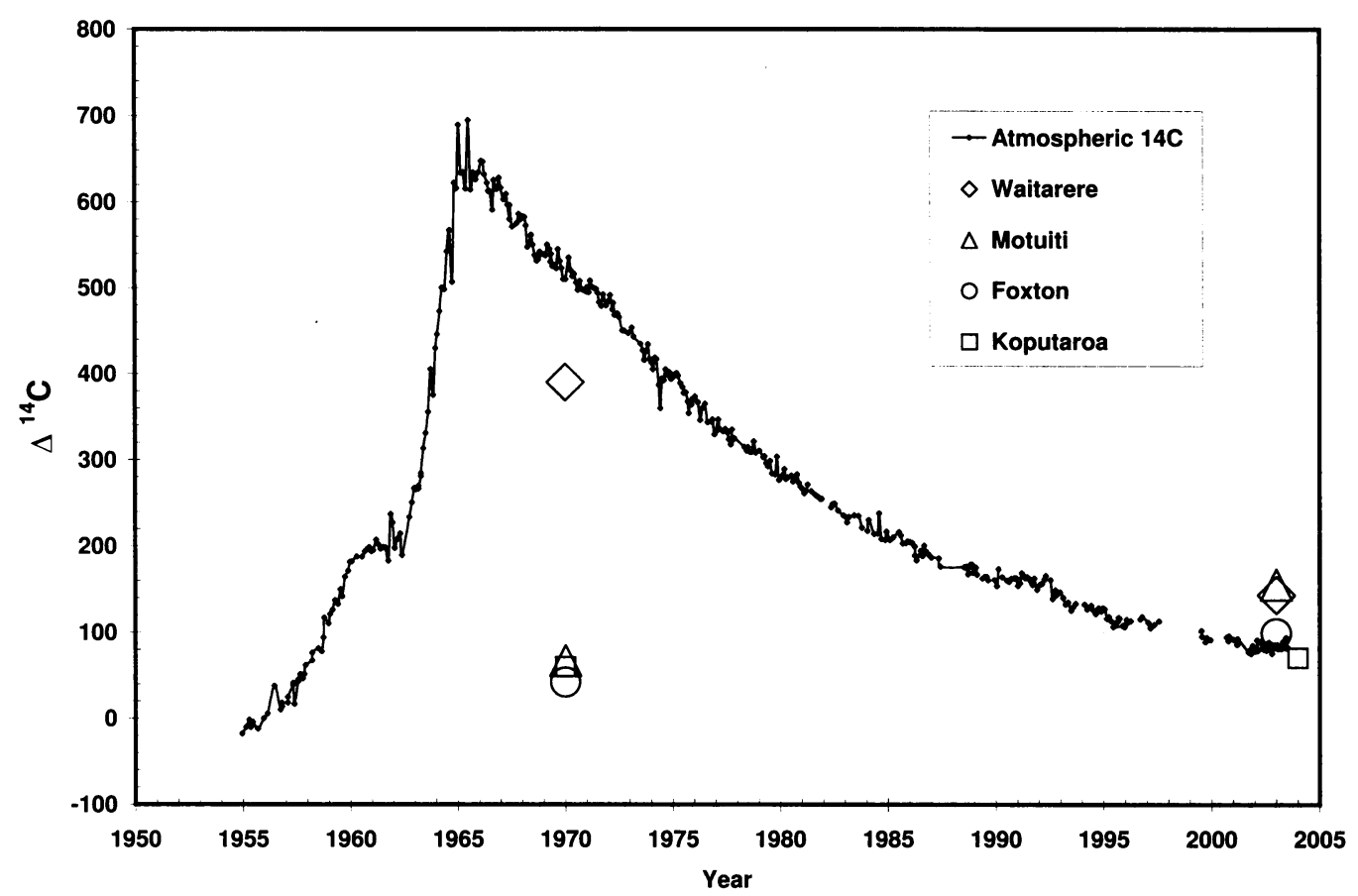

Figure 2 Surface soil $\Delta^{14} \mathrm{C}$ values for the 4 Manawatu chronosequence phases sampled in 1970 and $2003-4$ compared against the atmospheric $\Delta^{14} \mathrm{C}$ curve measured for the Southern Hemisphere. Atmospheric curve produced from $\mathrm{CO}_{2}$ collected from Wellington, New Zealand (M R Manning and W H Melhuish, private communication, 1993). 
The Waitarere phase soil has formed primarily after the early-1960s bomb- ${ }^{14} \mathrm{C}$ spike. The surface soil carbon showed incorporation of a larger proportion of bomb ${ }^{14} \mathrm{C}$ than any of the other soils (394\%o) (Table 1). Since this soil contains only unaltered sand with considerable roots and some coarse particulate organic matter, it is not surprising that a best-fit model suggests no passive SOM exists in this soil (Table 2). The box model suggests a residence time of $\sim 6 \mathrm{yr}$ for this soil-a result consistent with no mineral-organic interactions in this very young sandy soil. It must, however, be emphasized that this residence time should be used with caution since the model assumes the SOM pool sizes are approximately at steady state between 1970 and 2003.

Table 2 Residence times and passive fraction of the whole surface soils calculated using the box model.

\begin{tabular}{lccc}
\hline Phase & Soil age $(\mathrm{yr})$ & Fraction passive & Residence time $(\mathrm{yr})$ \\
\hline Waitarere & 80 & $0 \%$ & 6 \\
Motuiti & 1000 & $1 \%$ & 45 \\
Foxton & 3000 & $16 \%$ & 29 \\
Koputaroa & 10,000 & $26 \%$ & 16 \\
\hline
\end{tabular}

The remaining soils show a clear pattern of increasing proportions of passive SOC from $\sim 1 \%$ at $1000 \mathrm{yr}$ to $26 \%$ at $10,000 \mathrm{yr}$. This closely matches the expected rate of passive $\mathrm{C}$ accumulation for surface soils and therefore validates the concept that the box model can be used effectively to identify the size of the passive fraction when samples collected $\sim 1970$ are available to complement contemporary sampling. The results suggest that samples collected $\sim 1970$ may offer better constraints of C cycling rates than pre-bomb samples (e.g. Trumbore 1993; Trumbore et al. 1996). This could be of significance since samples collected around 1970 are more likely to be available than samples collected prior to 1962 .

Of equal interest is the decreasing trend in SOC residence times for the 1000 - to 10,000 -yr soils in Table 2. This trend suggests that SOC residence times decrease by a factor of 3 during this period of soil development. Since considerable accumulation of nutrients and alleviation of nutrient limitation occurs during this period of soil development, we expected to see broad differences in the chemistry of SOM between the Motuiti and Koputaroa soil.

Figure 3 illustrates broad differences in the chemical composition of the 2 soils determined through pyrolysis-GC/MS. The compound abundance in Figure 3 displays a strong pattern in which polysaccharide-derived peaks, such as furans, are substantially higher in the Koputaroa soil. In contrast, peaks representing various aromatic derivatives (e.g. phenols) including a number of specific lignin derivatives are higher at Motuiti. These chemical components from the py-GC/MS data are summarized in Figure 4, and suggest a shift from lignin-derived SOM (e.g. compounds such as vanillic acid, syringol, and guaiacol) at the young site (Motuiti) to more polysaccharide-derived SOM at the older site (Koputaroa). This indicates a substantial shift in litter inputs to the SOM pool during ecosystem development, beginning with poorer-quality lignin-rich litter under strongly nutrient-limited conditions early in soil development (Motuiti). After 10,000 yr of soil development (Koputaroa), nutrient limitation has largely been alleviated (Syers et al. 1970), presumably resulting in more decomposable plant litter inputs to soil, and more effective microbial decomposition. As a result, SOM appears to be more completely processed to various polysaccharide compounds, which we believe are generally of microbial origin. This pattern of strong nutrient limitation and low litter quality early in soil development and alleviation of this condition over 10,000 yr has not yet been overprinted by decades of stable pastoral management. However, the pattern of nutrient limitation may have been stronger at the young site under native forest and shrubland vegetation. 


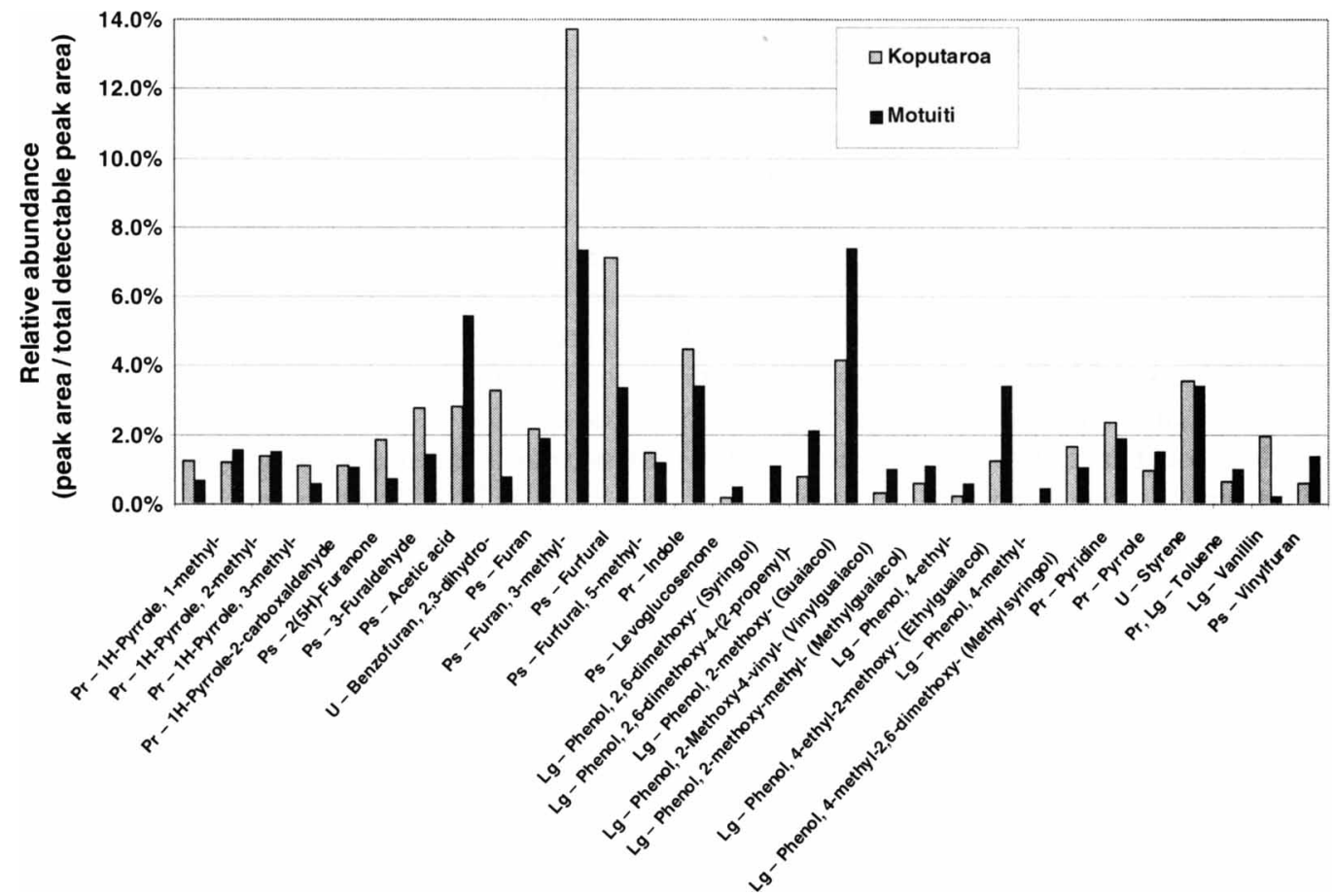

Figure 3 Pyrolysis-GC-MS analysis of 2 soils, showing peaks that account for more than $1 \%$ of the total ion count as well as selected additional peaks with known precursor molecules. The younger, Motuiti, is solid black bars, and the older, Koputaroa, is outlined. The relative (to total detectable peaks) abundance of each compound is given. The categorical codes refer to the precursor molecule for each compound and are: Ps, polysaccharide; Lg, lignin; Pr, protein; and U, unknown.

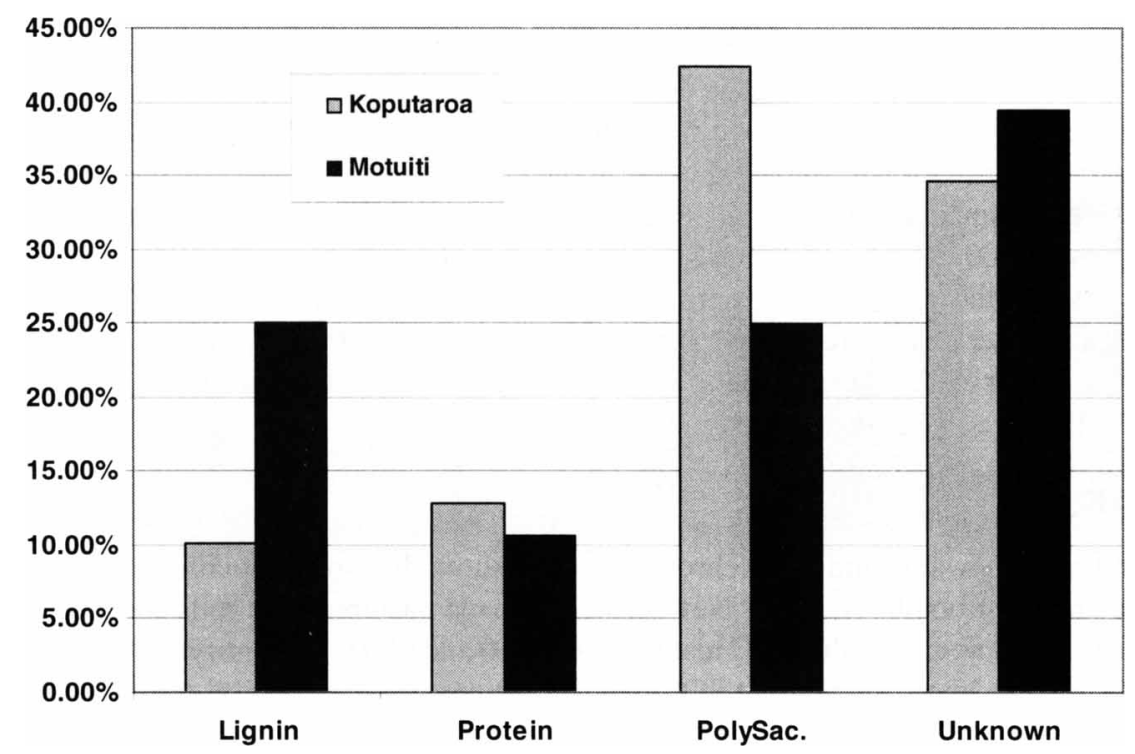

Figure 4 Chemical components of the pyrolysis-GC-MS data from Motutiti and Koputaroa soils 
The strong and sensible relationship between SOM turnover rates and chemistry measured by pyrolysis-GC/MS is worthy of further exploration given the importance given to lignin: $\mathrm{N}$ ratio and structural C in the CENTURY and RothC models, respectively (Parton et al. 1987; Jenkinson et al. 1990). These factors are different ways of describing litter quality and are used in the models to regulate the partitioning of fresh plant material entering soil between pools with rapid and decadal decomposition rates. The chemistry data appears to support these model structures by suggesting that considerable plant-derived lignin is retained under poor litter quality and low $\mathrm{N}$ conditions, while most SOM stabilized in more fertile, older soils is derived from microorganisms. This phenomenon should apply generally to chronosequences in which $\mathrm{N}$ accumulation occurs over hundreds or thousands of years and is limited by rates of $\mathrm{N}$ fixation and atmospheric deposition. In contrast, models generally assume that increasing soil clay content increases SOM residence times. The results from this chronosequence, in which clay increases with soil age due to mineral weathering and dust inputs (Syers and Walker 1969), suggest the opposite pattern exists. It is possible that the litter quality effect is more important than clay content, or it is possible that clay content is not an important determinant of C stocks or turnover rates in New Zealand soils (Percival et al. 2000). Correctly representing these effects in models of the soil $\mathrm{C}$ cycle has been studied considerably and remains at least somewhat unresolved. Our data suggests that even bulk $\Delta^{14} \mathrm{C}$ values from samples collected $\sim 5-15$ and $\sim 30-40$ yr after the bomb- ${ }^{14} \mathrm{C}$ spike have considerable potential to resolve the importance of these effects.

A comparison of $\Delta^{14} \mathrm{C}$ values for the different sequential density fractions separated from the surface levels of the Motuiti and Koputaroa soils is illustrated in Figure 5 . The $\geq 2.55 \mathrm{~g} / \mathrm{mL}$ fraction is very useful in identifying an older component of soil organic matter, accounting for $16 \%$ and $4 \%$ of recovered $\mathrm{C}$ at Motuiti and Koputaroa, respectively. The use of ${ }^{14} \mathrm{C}$ is normally equated with estimating residence times, but it is more important to establish the proportion of soil carbon with residence times that do (and do not) respond to global change. In Figure 6, we use the density fractionation to help separate the soil carbon into 2 pools in the $\sim 1000$-yr-old (Motuiti) and $\sim 10,000$-yr-old (Koputaroa) soils of the Manawatu sand dune chronosequence. The Motuiti data demonstrates that detailed density fractionation can provide an improved estimate of fraction passive, based on fitting bomb ${ }^{14} \mathrm{C}$ incorporation passive relative to performing the same procedure on bulk soil (Table 2). The results for the size of the "passive fraction" depicted in Figure 6 are also consistent with the expected accumulation of passive $\mathrm{C}$ expected in the chronosequence. The reasons for considerably larger passive $\mathrm{C}$ contents of the $\geq 2.55 \mathrm{~g} / \mathrm{mL}$ fraction remain unknown. Based on mineralogy data from samples SB10029A and SB09938A in the New Zealand National Soils Database, the heavy mineral fraction in these soils consists primarily of pyroxene and hornblendes, so different forms of mineral-organic interactions may govern the stabilization of $\mathrm{C}$ in these fractions and correspond to the generally higher SOC stocks found in soils formed on mafic as opposed to granitic parent materials (Jenny 1980).

\section{CONCLUSIONS}

Soils from the Manawatu sand dune chronosequence show that soil properties can strongly influence the retention of bomb ${ }^{14} \mathrm{C}$ under New Zealand grazed pastures. The soils show a clear pattern as a function of soil age, with the $\Delta^{14} \mathrm{C}$ results from 1970 and $2003-4$ quantifying the rate of passive SOM accumulation, and showing that SOM residence times decrease as soil fertility builds.

Py-GC/MS data support the $\Delta^{14} \mathrm{C}$-derived residence times by suggesting a shift from lignin-derived SOM at the young site (Motuiti) to polysaccharide-derived SOM at the older site (Koputaroa). This result suggests that classifications provided by py-GC/MS may have potential for calibration to ${ }^{14} \mathrm{C}$ derived turnover rates and use in process-based models. 


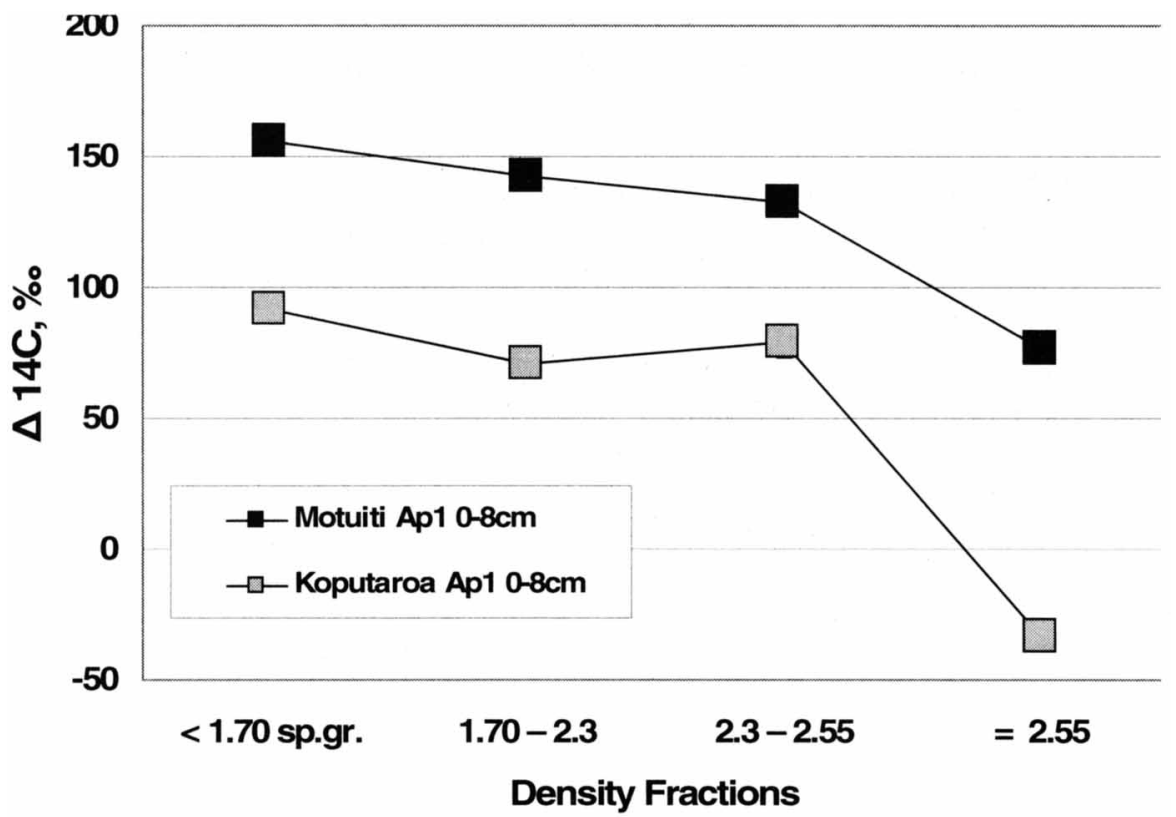

Figure 5 Comparison of $\Delta^{14} \mathrm{C}$ in the sequential density fractions separated from surface soils in 2 phases of the Manawatu chronosequence.

\section{Fraction Passive ( $\%$ of total C with millenial residence times)}

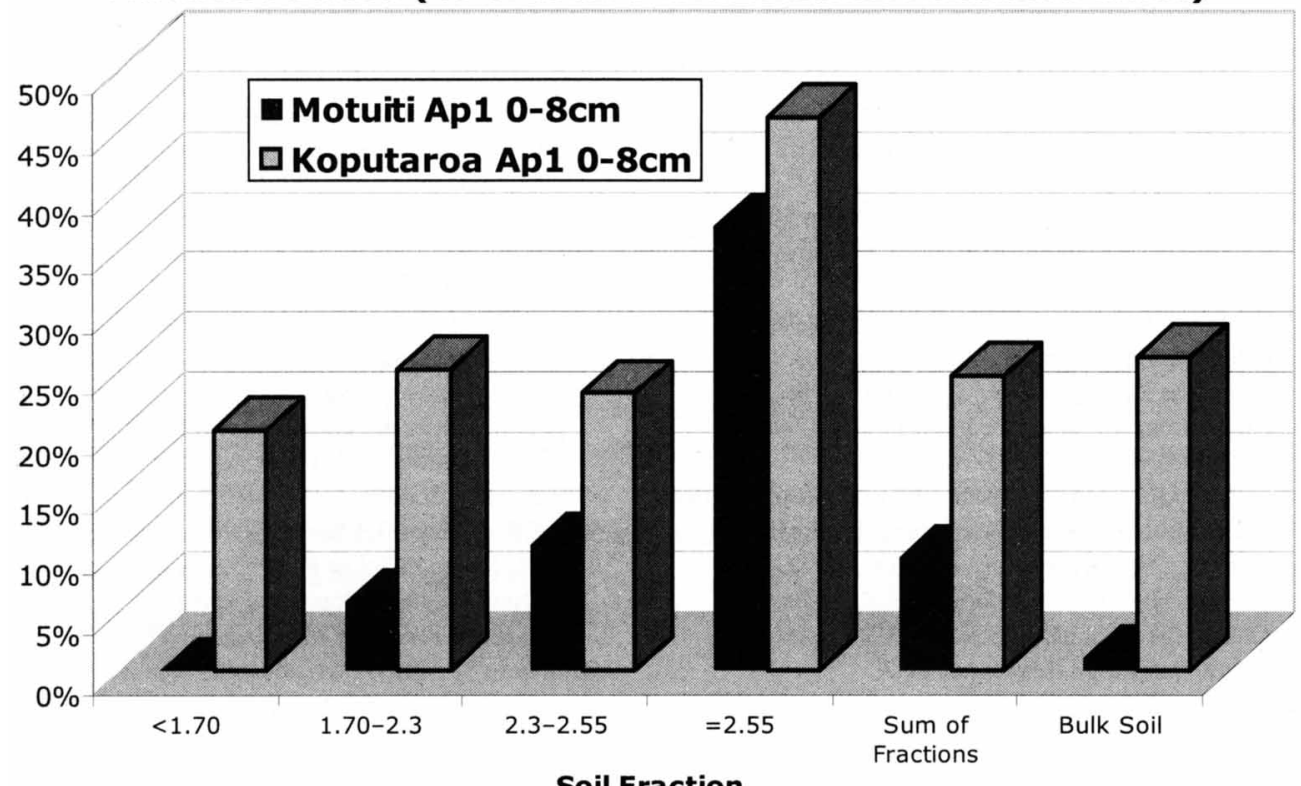

Figure 6 Density fractionation is used to separate soil carbon into 2 pools in the Motuiti and Koputaroa soils. The Motuiti data show that the density separation provides a better estimate of the passive fraction for the younger soil.

The young and old sites showed that the $\Delta^{14} \mathrm{C}$ values of soil density fractions follow a similar overall pattern of bulk $\Delta^{14} \mathrm{C}$ values between sites. We find that traditional separation of fractions $<2.55 \mathrm{~g} /$ 
$\mathrm{mL}$ yielded little meaningful differences between soil fractions, but the suggestion by Sollins et al. (2006) to examine a higher density fraction $(\geq 2.55 \mathrm{~g} / \mathrm{mL})$ appears to have stabilized distinctly more passive SOM in both soils.

\section{ACKNOWLEDGMENTS}

The authors would like to acknowledge funding for this research supplied by the New Zealand Foundation for Research Science \& Technology contract numbers C05X0202 and C09X0212, and Ministry for Environment in support of the US-NZ Climate Change Partnership. JCN thanks the A. Mellon Foundation for funding. We also thank Hugh Wilde, Kevin Tate, Suzanne Lambie, and Jon Carrasco for assistance in the field and lab.

\section{REFERENCES}

Amundson R. 2001. The carbon budget in soils. Annual Review of Earth and Planetary Sciences 29:535-62.

Baisden WT, Amundson R, Cook AC, Brenner DL. 2002. Turnover and storage of $\mathrm{C}$ and $\mathrm{N}$ in five density fractions from California annual grassland surface soils. Global Biogeochemical Cycles 16(4):1117, doi: 10.1029/2001/GB001822,2002.

Goh KM, Rafter TA, Stout JD, Walker TW. 1976. The accumulation of soil organic matter and its carbon isotope content in a chronosequence of soils developed on aeolian sand in New Zealand. European Journal of Soil Science 27(1):89-100.

Harden JW, Mark RK, Sundquist ET, Stallard RF. 1992. Dynamics of soil carbon during deglaciation of the Laurentide ice sheet. Science 258(5090):1921-4.

Jenkinson DS, Andrew SPS, Lynch JM, Goss MJ, Tinker PB. 1990. The turnover of organic carbon and nitrogen in soil. Philosophical Transactions Royal Society London B 329(1255):361-8.

Jenny H. 1941. The Factors of Soil Formation: A System of Quantitative Pedology. New York: McGraw-Hill. $281 \mathrm{p}$.

Jenny H. 1980. The Soil Resource: Origin and Behavior. New York: Springer-Verlag. 377 p.

Lassey KR, Tate KR, Sparks RJ, Claydon JJ. 1996. Historic measurements of radiocarbon in New Zealand soils. Radiocarbon 38(2):253-70.

Manning MR, Gomez AJ, Pohl KP. 1994. Atmospheric $\mathrm{CO}_{2}$ record from in situ measurements at Baring Head. In: Trends: A Compendium of Data on Global Change. Carbon Dioxide Information Analysis Center, Oak Ridge National Laboratory, US Department of Energy, Oak Ridge, Tennessee, USA.

O'Brien BJ, Stout JD. 1978. Movement and turnover of soil organic matter as indicated by carbon isotope measurements. Soil Biology and Biochemistry 10(4): 309-17.

Parton WJ, Schimel DS, Cole CV, Ojima DS. 1987. Analysis of factors controlling soil organic matter levels in Great Plains grasslands. Soil Science Society of America Journal 51(5):1173-9.
Percival HJ, Parfitt RL, Scott NA. 2000. Factors controlling soil carbon levels in New Zealand grasslands: Is clay content important? Soil Science Society of America Journal 64(5):1623-30.

Pouwels AD, Eijkel GB, Boon JJ. 1989. Curie-point pyrolysis-capillary gas chromatography-high-resolution mass spectrometry of microcrystalline cellulose. Journal of Analytical and Applied Pyrolysis 14(4): 237-80.

Schlesinger WH. 1990. Evidence from chronosequence studies for a low carbon-storage potential of soils. $\mathrm{Na}$ ture 348(6298):232-4.

Schulten H-R, Schnitzer M. 1997. The chemistry of soil organic nitrogen: a review. Biology and Fertility of Soils 26(1):1-15

Sollins P, Swanston C, Kleber M, Filley T, Kramer M, Crow S, Caldwell BA, Lajtha K, Bowden R. 2006. Organic $\mathrm{C}$ and $\mathrm{N}$ stabilization in a forest soil: evidence from sequential density fractionation. Soil Biology and Biochemistry 38(11):3313-24.

Syers JK, Walker TW. 1969. Phosphorous transformations in a chronosequence developed on wind-blown sand in New Zealand: I. Total and organic phosphorus. European Journal of Soil Science 20(1):57-64.

Syers JK, Adams JA, Walker TW. 1970. Accumulation of organic matter in a chronosequence of soils developed on wind-blown sand in New Zealand. European Journal of Soil Science 21(1):146-53.

Tate KR, Giltrap DJ, Claydon JJ, Newsome PF, Atkinson IAE, Taylor MD, Lee R. 1997. Organic carbon stocks in New Zealand's terrestrial ecosystems. Journal of The Royal Society of New Zealand 27(3):315-35.

Trumbore SE. 1993. Comparison of carbon dynamics in tropical and temperate soils using radiocarbon measurements. Global Biogeochemical Cycles 7(2):27590.

Trumbore SE, Chadwick OA, Amundson R. 1996. Rapid exchange between soil carbon and atmospheric carbon dioxide driven by temperature change. Science 272(5260):393-6. 